\title{
Treatment of Effluents from lons of Heavy Metals as Display of Environmentally Responsible Activity of Modern Businessman
}

\author{
Myroslav Malovanyy ${ }^{1}$, Halyna Sakalova ${ }^{2 *}$, Tamara Vasylinycz ${ }^{2}$, \\ Olha Palamarchuk ${ }^{3}$, Jaroslav Semchuk ${ }^{4}$
}

1 Viacheslav Chornovil Institute of Sustainable Development, Lviv Polytechnic National University, S. Bandera Str. 12, Lviv, 79013, Ukraine

2 Natural Sciences and Geography Faculty, Vinnytsia Mykhailo Kotsiubynskyi State Pedagogical University, Ostrozhskogo street 32, Vinnytsia, 21100, Ukraine

3 Educational and Scientific Institution of Pedagogy, Psychology, Training of Specialists of Higher Qualification, Vinnytsia Mykhailo Kotsiubynskyi State Pedagogical University, Ostrozhskogo street 32, Vinnytsia, 21100, Ukraine

4 Institute of Petroleum Engineering, Ivano-Frankivsk National Technical University of Oil and Gas, Karpatska str., 15 Ivano-Frankivsk, Ukraine 76019, Ukraine

* Corresponding author's e-mail: sakalovag@gmail.com

\begin{abstract}
This work is dedicated to the development of scientific technologies of sewage water clarification of different industrial enterprises from chrome and nickel ions through adsorption by bentonite from Cherkasy field under dynamic conditions. The perspective and efficiency of application of bentonite clays for treatment of sewage water are confirmed by their advantages over other sorbents, that is: they win in accessibility, cost, and possibility of regeneration and multiple usages. The studies proved the expediency of bentonite clays usage for treatment of sewage water from chrome (III), zinc (II) and nickel(II) ions. The static activities were determined and isotherms of adsorption of nickel, zinc and chrome ions were built. Deposition by gravity was chosen as the most optimal method reset of spend sorbent. Dosage of flocculants allows accelerating the process and increasing the degree of deposition. The basic parameters of the precipitation process of the used sorbent were established. The technological schemes of drain water purification from heavy metal ions contamination were developed; in addition to the following sedimentation and regeneration of sorbents.
\end{abstract}

Keywords: ecological safety, natural clay sorbents, adsorption, sedimentation, regeneration, ions of heavy metals.

\section{INTRODUCTION}

The reasons for the contamination of surface and underground waters in Ukraine are an increase in the number of reservoirs, trenches, landfills, which accumulate about 1500 tons of solid waste annually. Potentially dangerous are the depositories and grounds for the storage sites for galvanic production of a number of industrial plants and large cities, especially those containing electroplating sludge with precipitating lime (3 classes of danger) and the sludge obtained during the process of the electro-coagulative cleaning and at the use of ferriferous reagents ( 2 classes of danger). Heavy metals infiltrates into groundwater, washed off with sewage and percolate into natural water bodies. The accumulation of these connections in an organism negatively affects vitally important functions of aquatic lives. In addition, high maintenance of heavy metal ions prevents the use of water in a number of technological processes. One of the ways to mitigate the environment pollution by wastewater is the application of modern efficient treatment technologies, such as membrane technologies (Goncharuk et al., 2009, Seminska et al., 2016), ultrasound 
(Starchevskyy et al. 2017, Starchevskyy et al. 2018), adsorbtion on natural sorbents of mineral (Sabreen et al., 2014, Vasylechko et al., 2003) as well as plant (Danchenko et al. 2017) origin, and electroextraction (Gomelya et al., 2018) In this regard, the ecologically responsible activity of a modern entrepreneur, which is based on creating a new ecological and economic environment, becomes of particular relevance, provides for the change of existing norms and stereotypes of social and economic activity due to its ecologization, determines the conditions for creating the attractiveness of ecological and economic activity (economic benefits through environmental initiatives, proposals and responsibilities).

The ecologically responsible activity of a modern entrepreneur involves the removal of radioactive, toxic and valuable impurities from aqueous solutions through sorption separation. Special advantages of the ion-exchange methods are visible in the cases where the initial concentration of undesirable impurities is relatively small, and the degree of their extraction should be high.

The analysis of recent publications (Sabreen et al. 2014, Malyovanyy et al. 2013, Gaouar et al. 2015) shows the expediency of applying modern adsorption methods by entrepreneurs for the purification of wastewater from pollutants using natural disperse minerals as adsorbents. Purification of aqueous solutions with the help of disperse sorbents testifies to the psychological readiness of business entities to adopt systemic environmental innovations and build their own model of environmentally-friendly business activity that meets the requirements of environmentally friendly and energy saving production on this basis. Powerful geological reserves, cheap mining, easy preparation for transportation and use, the possibility of using spent sorbents in other technologies constitute the main advantages of using modern miners' entrepreneurs (Adamenko et al. 2017, Fiaizullina et al. 2017).

There are over 110 deposits of bentonites in Ukraine. The state balance of the Ukraine's reserves includes 6 deposits (Gorbkivske, Kudrinsk, Cherkassy, Kurtsevske, Berezhany, Pyzhivske), the stocks of which are classified according to the categories A $+\mathrm{B}+\mathrm{C} 1-60624$ thousand tons, $\mathrm{C} 2-221$ thousand tons, balanced stocks by the categories $\mathrm{B}+\mathrm{C} 1+\mathrm{C} 2$ is 1,415 thousand tons. Currently, only three fields are being developed: Gorbkivske, Kudrinskaya and Cherkassy, which makes up about $86 \%$ of the country's reserves and gives the main percentage of extraction of bentonite raw materials. Kurchetskoye, Berezhany and Pyzhivsk deposits are currently closed.

Cherkassy deposit of bentonite and paligorskite clays is located on the territory of Zvenigorod and Zhashkiv districts of Cherkasy region and partly on the territory of Taraschansky and Stavishchensky districts of Kyiv region. It is located regionally in the central part of the Ukrainian Crystal Shield. The deposit, with an area of approximately $700 \mathrm{~km}^{2}$, has a continuous spread, with the exception of the erosion areas in river valleys and deep beams (Figure 1).

The deposit was opened in 1954, the reserves of clay in the productive strata were estimated at 22,000 million tons, and its capacity is $0.5-43$ meters. Its productive thickness at the initiative of the explorers is divided into five layers. The first layer is a dark-gray polymineral clay with a large amount of carbonates. This layer has a continuous occurrence and an average thickness of $14.1 \mathrm{~m}$. The second layer has an average thickness of $5.9 \mathrm{~m}$, composed mainly of bentonite clay, and has the greatest economic value among other layers. The third layer consists of four main lenses and has an average thickness of $2.7 \mathrm{~m}$. It is composed of paligorskite clay. The fourth layer of the field with a capacity of 1.7 $\mathrm{m}$ is composed of a genetic mixture of bentonite and paligorskyt. The fifth layer is the lowest part of the productive strata of the deposit, which lies in the form of individual lenses. This layer has an average thickness of $2.3 \mathrm{~m}$ and is composed of hydromicas with admixtures of sand and montmorillonite (Petrus et al. 2005, ).

Clay minerals form a group of layered and layered belt silicates, the particles of which have a clearly expressed crystalline structure and sizes no larger than $0.5-5$ microns. The dispersibility of crystals of clay minerals is the criterion that determines their basic physical and chemical properties: sorption ability, ion exchange, catalytic action, thixotropic coagulation structure, i.e., the properties associated with the effective surface of crystals (Petrushka et al. 2014).

The chemical composition of Cherkassy deposits is shown in Table 1.

Classification of clay is based on the principle of minerals systematization by the characteristics of their crystalline structure. There are the following types of clay: clay type 1: 1 , 


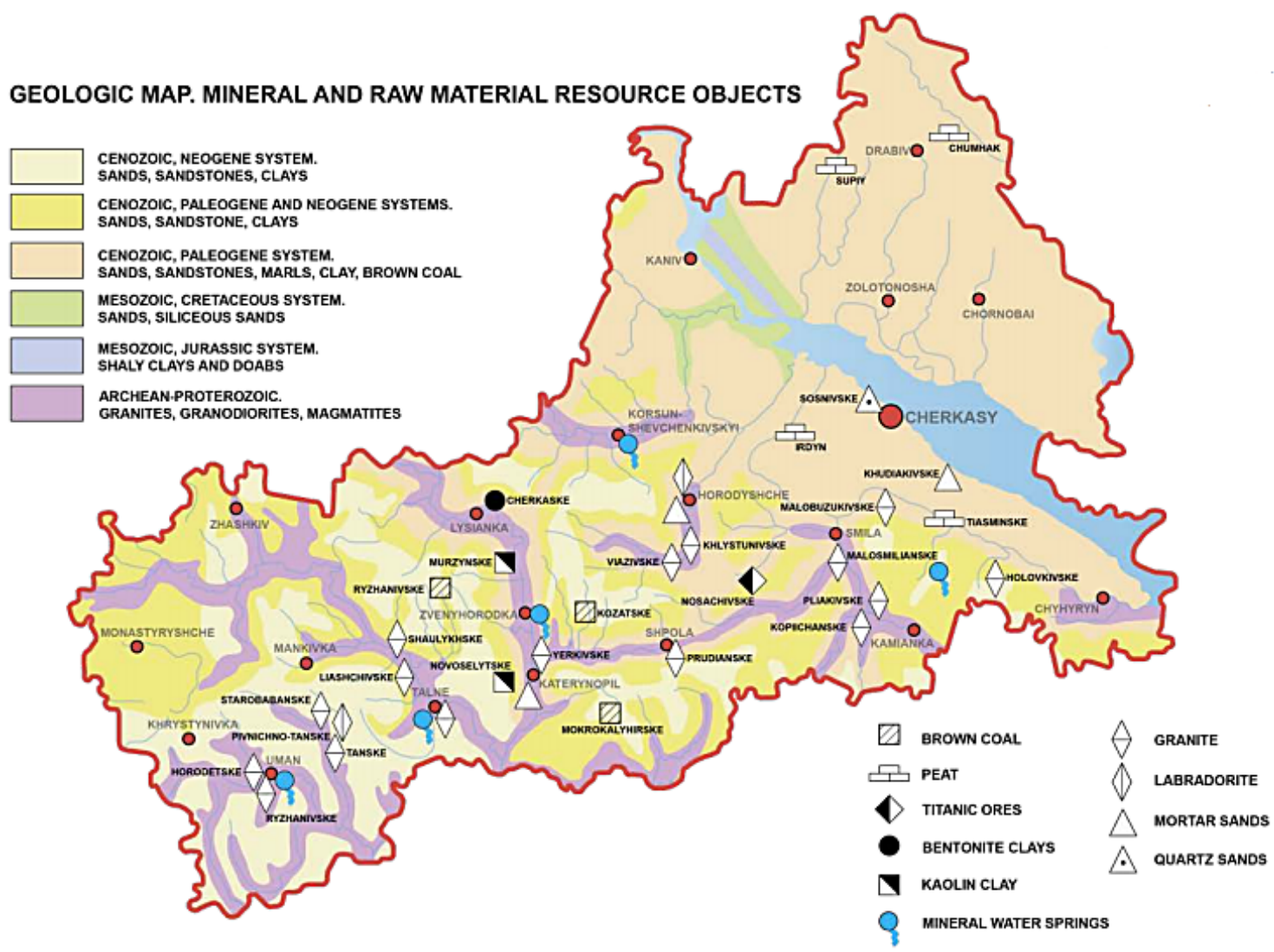

Figure 1. Map of the Cherkasy region

the main representative of which are kaolinite; clay type $2: 1$, among which the main place belongs to the swell (montmorillonite, saponite and others) and non-swelling clay - hydromicans; clay type 2: 1: 1; layer-belt silicates, which include paligorsk. The bentonite (type 2: 1) and paligorskite (type of laminate-strip silicates) from the Cherkassy deposit of bentonite and paligorskite clays was used for the study.
The purpose of the work was to carry out experimental studies on the adsorption characteristics of nickel (II), zinc (II) and chromium (III) ions on the bentonite clays of Cherkassy deposit, identification of the experimental data from existing theoretical models and increase the intensity of depletion of the spent sorbent by aggregating particles due to the introduction into the flocculant system.

Table 1. The average chemical composition of Dashukiv's quarry (in $\%$ by weight)

\begin{tabular}{|c|c|c|c|c|c|}
\hline Component & 1 horizon & 2 horizon & 3 horizon & 4 horizon & 5 horizon \\
\hline $\mathrm{SiO}_{2}$ & 48.6 & 59.92 & 55.2 & 58.89 & 56.05 \\
\hline $\mathrm{Al}_{2} \mathrm{O}_{3}$ & 13.73 & 14.78 & 11.74 & 11.05 & 13.30 \\
\hline $\mathrm{TiO}_{2}$ & 0.72 & 0.75 & 0.34 & 0.55 & 0.62 \\
\hline $\mathrm{Fe}_{2} \mathrm{O}_{3}$ & 5.98 & 6.95 & 6.95 & 6.24 & 7.46 \\
\hline $\mathrm{FeO}$ & 0.49 & 0.07 & 0.2 & 0.2 & 0.42 \\
\hline $\mathrm{MnO}$ & 0.05 & 0.08 & 0.34 & 0.18 & 0.04 \\
\hline $\mathrm{MgO}$ & 2.71 & 2.26 & 5.08 & 1.31 & 3.49 \\
\hline $\mathrm{CaO}$ & 8.84 & 1.73 & 1.25 & 4.47 & 1.18 \\
\hline $\mathrm{Na}_{2} \mathrm{O}$ & 1.53 & 0.35 & 0.26 & 0.44 & 0.09 \\
\hline $\mathrm{K}_{2} \mathrm{O}$ & 1.16 & 0.23 & 1.12 & 1.14 & 3.21 \\
\hline $\mathrm{SO}_{3}$ & 0.23 & 0.15 & 0.1 & 0.15 & 0.24 \\
\hline $\mathrm{P}_{2} \mathrm{O}_{5}$ & 0.07 & 0.05 & 0.055 & 0.06 & 0.06 \\
\hline $\mathrm{B} . \mathrm{n}$ ח. & 12.89 & 8.42 & 11.76 & 11.35 & 6.32 \\
\hline $\mathrm{Total}$ & 97 & 100 & 98.85 & 98.7 & 101.3 \\
\hline
\end{tabular}




\section{MATERIALS AND METHODS}

The chosen method for the adsorption of heavy metal ions by adding the sorbent into a solution and periodically mixing provides a maximum contact area between phases, which allows for the full use of the absorbing capacity of the sorbent (Kołodyńska et al. 2017). The disadvantage of this method is the need to clean the treated water from the spent sorbent. The most expedient in this case is the separation of sorbent and water under the influence of gravity.

For establishment of range of regime parameters afterwards, it was necessary to conduct the detailed research of the adsorption processes. Series of previous experiments were the executed that gave an opportunity to draw the following conclusions:

1. fluctuations of temperature from +10 to $+30^{\circ} \mathrm{C}$ do not show a noticeable influence on the degree of adsorption of ions of heavy metals by clays;

2. the maximum absorption of chromium, nickel and zinc ions occurs within 30 minutes, and practically complete - in 6-8 hours;

3. a rational amount of dosing is $5-8 \mathrm{~g}$ of bentonite per $1 \mathrm{dm}^{3}$ of contaminated water (provided that the initial concentration of the pollutant does not exceed $1000 \mathrm{mg} / \mathrm{dm}^{3}$ ).

4. under the conditions of constant mixing (with the speed of the mixer 70-80 per minute), the absorption of chromium ions is $87.2 \%$, zinc ions are $89.8 \%$ and the smallest nickel ions (80.4\%).

In order to describe the experimental data, an isotherm equation was used to describe as monomolecular adsorption; and more complex processes (isotherms L-type). The correspondence of the experimental data to the theoretical model was determined from the graphic dependences, including the deviation of the experimental points from the calculated adsorption values (Fig. 4), as well as the dispersion value $(\sqrt{ } \sigma 2)$ and the value of Fisher's criterion (F) (Warchoł and Petrus 2006) (Table 2).

The analysis of the results shows that the process of adsorption of pollutants by clay materials is non-uniform. (Malovanyy et al. 2013, Malovanyy et al. 2014) As can be seen from the results presented in the table, the individual isotherm best describes the sorption of each adsorbate. Thus, the sorption of nickel ions is best described by the Dubinin-Radushkevich isotherm, the chromium ions - the isothermal bi-Langmuir, and the zinc ions - the Langmuir isotherm.

The universal model describing the sorption of heavy metal ions by the clay sorbent was chosen with due certainty the Langmuir isotherm, and the process itself deserves to be described by the theory of monomolecular adsorption. In the coordinates of Langmuir, the equations have the following form:

$$
\begin{array}{ccc}
\mathrm{Y}=0.063 \mathrm{X}_{i} /\left(1+0.00012 \mathrm{X}_{i}\right) & \text { chrome } & \text { (1), } \\
\mathrm{Y}=0.014 \mathrm{X}_{\mathrm{i}} /\left(1+0.00013 \mathrm{X}_{i}\right) & \text { nickel } & \text { (2), } \\
\mathrm{Y}=0.036 \mathrm{X}_{i} /\left(1+0.0002 \mathrm{X}_{i}\right) & \text { zinc }
\end{array}
$$

Natural sorbents have a developed porous structure, which manifests itself in a large variation in the density of various particles. In this connection, the process of precipitation of sorbent in water under the action of gravity is quite long (Vasylechko et al. 2003). We proposed to increase the intensity of the spent sorbent depletion by aggregating particles due to their agglomerization as a result of introduction into the flocculant system. Polyacrylamide (PAA) is a well-proven, polymeric coagulant, chemically inert to bentonite with fairly high flocculation properties.

For flocculation adsorbent it is recommended to use $2 \%$ working solutions of coagulants. In order to prepare these solutions, a $15 \%$ solution of polymer was added in a volume of $13.3 \mathrm{~cm}^{3}$ and brought to $100 \mathrm{~cm}^{3}$ distilled water in a volumetric flask.

During the experiment, the effect of flocculant, namely, polyacrylamide (PAA), on the degree of adsorption was determined as well to study the effect of flocculant on the degree of adsorption in model solutions containing heavy metal ions and adsorbent, doses of PAA at different time intervals of the process. The research was carried out for model solutions with investigated heavy metal ions (Ni, Cr, Zn) and for their different initial concentrations. In order for the flocculation to occur quickly and throughout the volume of the solution, the system was intensively mixed in a certain mode in electromagnetic mixers.

\section{RESULTS AND DISCUSSION}

Figure 2 shows the results of research for model solutions, with a concentration of nickel ions $250 \mathrm{mg} / \mathrm{dm}^{3}$ of dosing solution of PAA was $2 \mathrm{ml}$. The PAA solution was dosed accordingly at the beginning of the process (1), after 5 (2) and 10 (3) hours. 
Table 2. Comparison of statistical estimates for the identification of experimental data for theoretical models

\begin{tabular}{|c|c|c|c|}
\hline \multirow{2}{*}{ Criteria of statistical estimation } & \multicolumn{3}{|c|}{ Persorption of ions of heavy metal } \\
\hline & $\mathrm{Ni}^{2+}$ & $\mathrm{Gr}^{3+}$ & $\mathrm{Zn}^{2+}$ \\
\hline \multicolumn{4}{|c|}{ Isotherms of Langmuir } \\
\hline$\sqrt{\sigma^{2}}$ & 1.469 & 1.448 & 0.4594 \\
\hline $\mathrm{F}$ & 4.562 & 5.878 & 44.69 \\
\hline \multicolumn{4}{|c|}{ Isotherms of $\mathrm{Bi}$ - Langmuir } \\
\hline$\sqrt{\sigma^{2}}$ & 1.854 & 0.561 & 10.96 \\
\hline $\mathrm{F}$ & 2.868 & 39.18 & 0.1835 \\
\hline \multicolumn{4}{|c|}{ Isotherms of Langmuir - Freundlich } \\
\hline$\sqrt{ } \sigma^{2}$ & 1.47 & 12.14 & 7.796 \\
\hline $\mathrm{F}$ & 4.559 & 0.834 & 0.3724 \\
\hline \multicolumn{4}{|c|}{ Isotherms of Marchevsky - Yaronets } \\
\hline$\sqrt{\sigma^{2}}$ & 1.47 & 12.147 & 7.699 \\
\hline $\mathrm{F}$ & 4.560 & 0.837 & 0.3725 \\
\hline \multicolumn{4}{|c|}{ Isoterm of Dubinin-Radushkevich } \\
\hline$\sqrt{ } \sigma^{2}$ & 0.4388 & 8.812 & 12.57 \\
\hline $\mathrm{F}$ & 51.13 & 0.1588 & 0.1396 \\
\hline \multicolumn{4}{|c|}{ Isotherm of Freindlich } \\
\hline$\sqrt{ } \sigma^{2}$ & 4.074 & 9.522 & 4.675 \\
\hline $\mathrm{F}$ & 0.5934 & 0.136 & 1.01 \\
\hline
\end{tabular}

The given data testify that the introduction of PAA solution into the system helped slowing the sorption process. This could be due to agglomerations of clay particles in the process of flocculation, resulting in a decrease in the surface of the mass transfer and their absorption capacity. Additionally, the process of desorption of pollutants due to cation exchange is not excluded, but the main reason for the deceleration that should be considered is the colloidal protection of clay chastines. Therefore, it is advisable to make a solution of PAA at the end of the process.

The kinetics of the precipitation process can be estimated accurately only by means of experimental research. The studies on the kinetics of deposition were carried out in this way. After the last mixing of the prototype samples, a solution of PAA was added to the system. During a certain time interval, the turbidity of the solution was determined - the sample was taken at

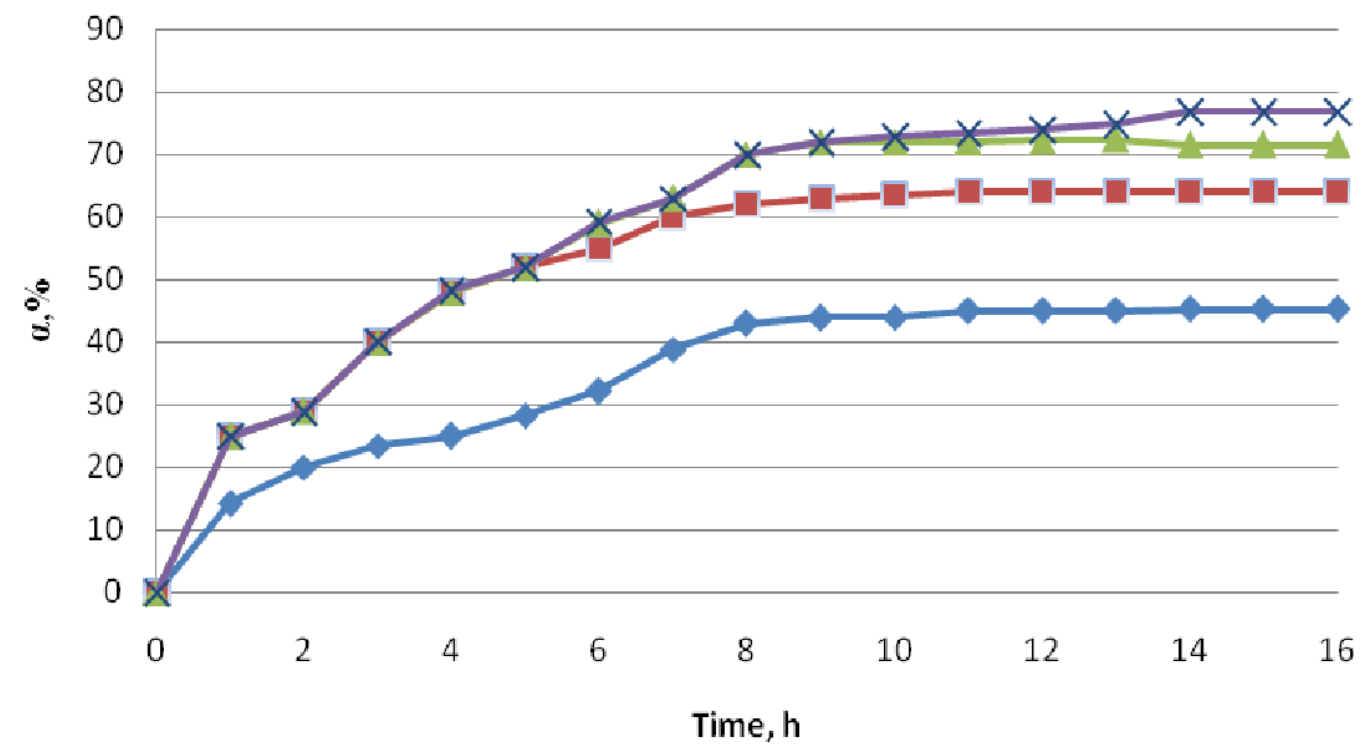

Figure 2. Dependence of the degree of adsorption of nickel ions (II) depending on the dosage of PAA: $--1 ;-\mathbf{\square}-2 ;-\mathbf{\Delta}-3 ;-\times-4$ (without PAA). 
the top of the solution. Experiments were carried out on a photoelectrocolorimeter with a green filter $(\lambda=530 \mathrm{~nm})$. In order to obtain standard solutions based on which the calibrated curve was constructed, a certain amount of sorbent was mixed with water and a solution of PAA to obtain a homogeneous suspension. Since the dose of PAA in the solution is insignificant $(2-5 \mathrm{ml}$ of $2 \%$ solution), its concentration was neglected. The specific absorption rate was determined by the experimental method and the corresponding values were obtained (Table 3):

The results of experimental studies on the kinetics of precipitation of sorbents in an aqueous medium that was purified under the conditions of their different initial content are presented as graphic dependences of sorbent concentration in water from the time of the process (Figs 3, 4).

The results of studies indicate that at the initial moment of time, the most intense deposition of particles of large fractions takes place (40 minutes). This period corresponds to a rapid decrease in the concentration of sorbent in water. Furthermore, the intensity of purification is significantly reduced and is determined by the rate of precipitation of particles of the smallest fraction.

The comparison of the graphic dependence presented above enables to argue that the dosage of the solution of PAA can reduce the deposition time by 20 minutes and increase the deposition rate by an average of $30 \%$. Within each graph there is a better precipitation of adsorbent saturated with heavy metal ions compared to the clay-water system, which is most likely due to an increase in the size of saturated clay particles. However, the nature of the metal ion does not significantly affect the rate of deposition.

It is important to determine the rate of precipitation of sorbent particles in order to realize the practical tasks of water purification from suspended matter. Therefore, for the studied systems, we calculated such parameters as average and fictitious velocities ( $\mathrm{Ua}$ and Uf), as well as the relative amount of the resulting sediment (Melnyk L. et al. 2015).
The experimental data show that the limiting step of the purification process is the deposition of the smallest fractions; therefore, the estimation of the rate of precipitation of particles of the adsorbent was carried out precisely for this period. For the value of the initial mass content of the sorbent in water, its value was taken for the moment of transition of the process of constant low intensity of precipitation. For bentonite, this period lasted approximately within $25 \div 30$ minutes. Starting from the specified time, the precipitation process is characterized by a linear dependence. The results of calculations are given in Table 4.

The resulting values can be used to calculate and select the purification equipment. Summarizing the results obtained, it can be argued that the dosage of PAA increases the average and percent rate of deposition. This, in turn, allows us to recommend flocculation deposition for the intensification of integrated technology for the treatment of effluents from heavy metals by adsorption of natural disperse sorbents in general.

In our opinion, using theoretical developments and data of experiments, it is expedient to use a technological scheme of purification, which provides for additional water purification after reagent deposition and removal of sediment. In the case of concentration of heavy metal ions in water to $0.3 \div 0.5 \mathrm{~g} / 1$, adsorption purification is carried out without additional reagent deposition (cycle 1-6). A simplified scheme can be used to clean sewage from fur production and etching dyeing.

Using the results of our research, we can propose a technological scheme of sewage treatment on the basis of a natural sorbent - bentonite - in full cycle (1-10). Such a principle scheme for purifying the liquid waste of the galvanic line, or sewage after the tanning of leather production is given in Fig. 5

Wastewater through the collector (1), where the alignment of the composition of the JI from various technological operations is fed into the tank (6). The reactor (7) for chemical deposition is supplied with the sewage from the settling tank (6), a solution of calcium hydroxide (8), and after an hour of intense mixing, a synthetic

Table 3. Value of Specific Absorption Rate $E$

\begin{tabular}{|c|c|c|c|c|}
\hline \multirow{2}{*}{ Characteristics of an adsorbent } & \multicolumn{4}{|c|}{ Available ions of heavy metals in solution } \\
\cline { 2 - 5 } & - & $\mathrm{Cr}^{3+}$ & $\mathrm{Ni}^{2+}$ & $\mathrm{Zn}^{2+}$ \\
\hline Bentonite & 0.0193 & 0.0219 & 0.0221 & 0.0224 \\
\hline Bentonit + PAA & 0.0208 & 0.0223 & 0.0225 & 0.0225 \\
\hline
\end{tabular}




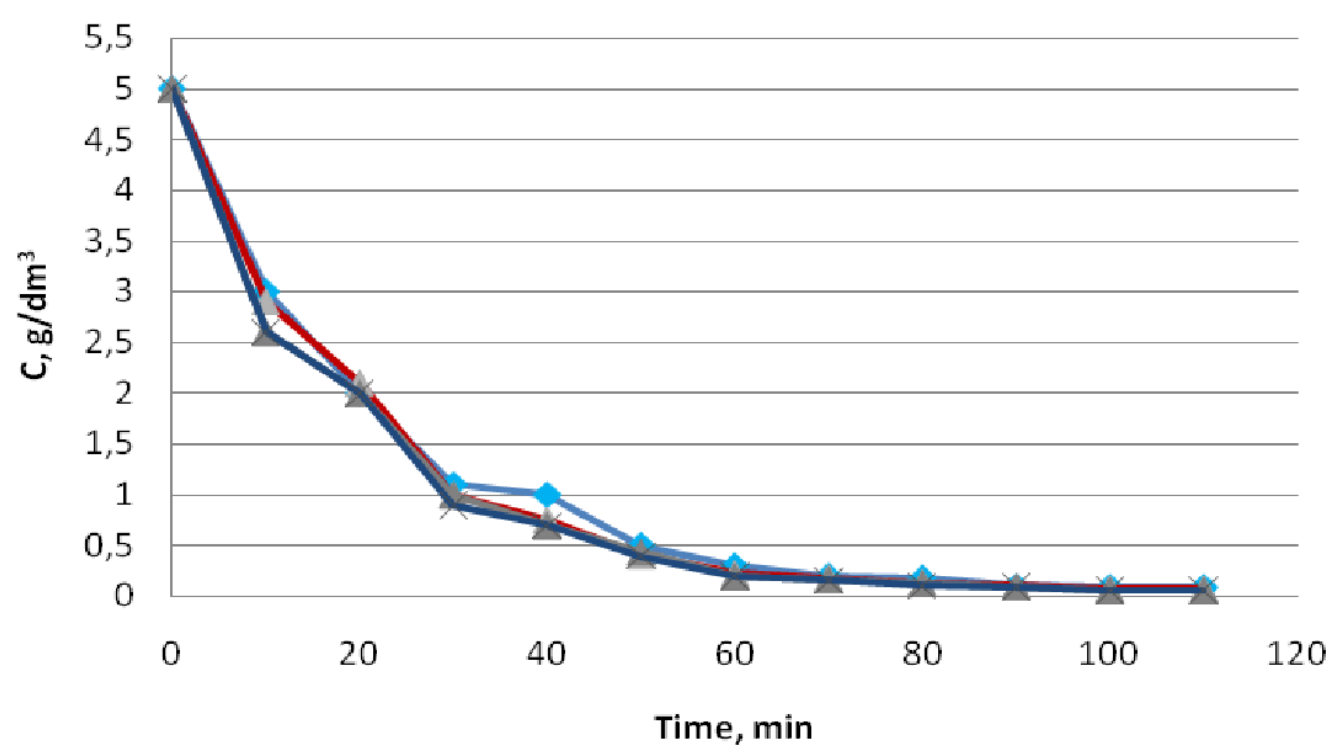

Figure 3 - Kinetics of precipitation of bentonite, $g$ / 1, without dosage of PAA (Avail-

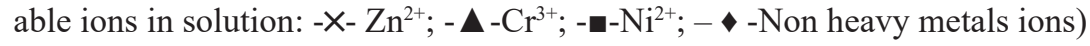

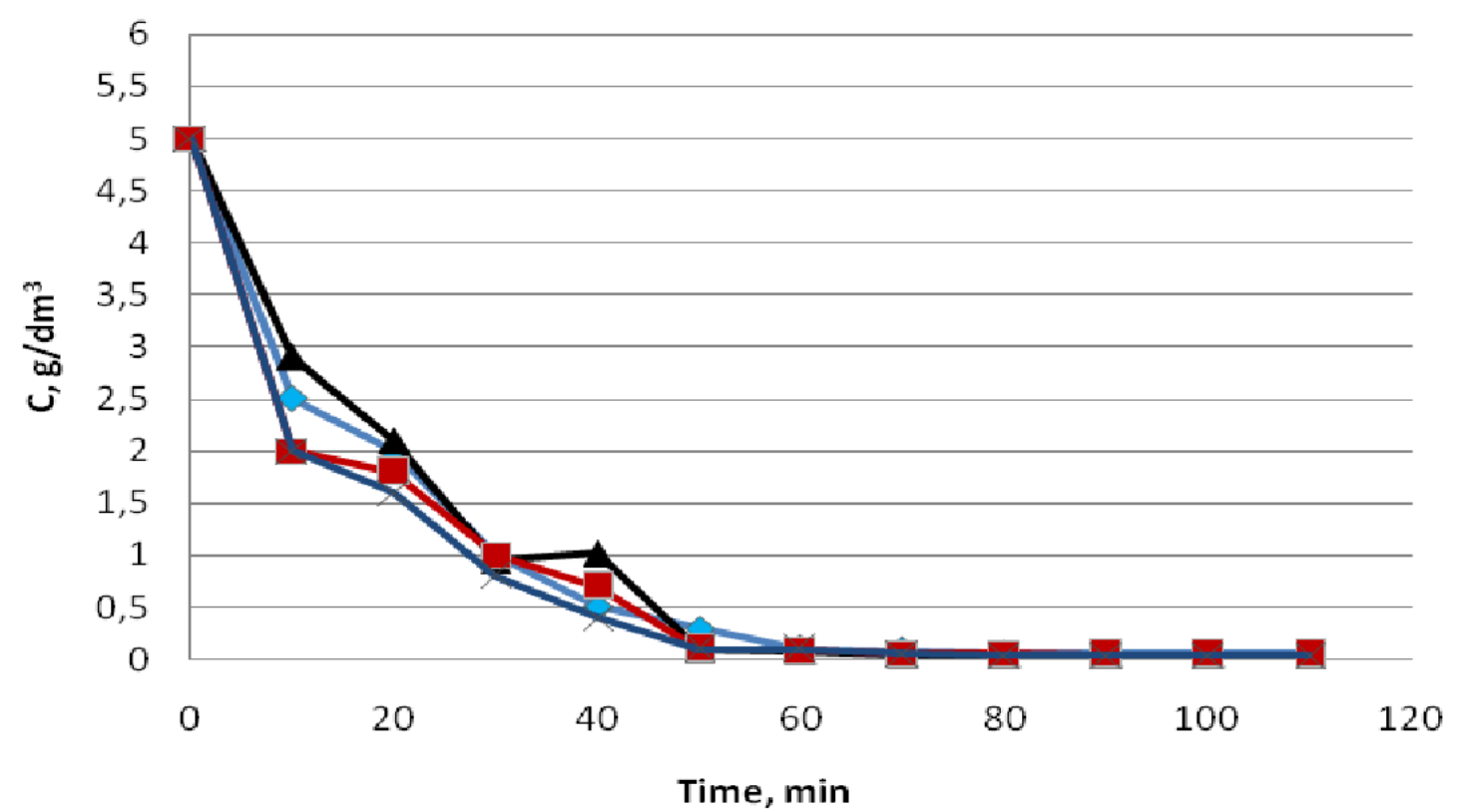

Figure 4 - Kinetics of precipitation of bentonite, $g$ / 1, with a dosage of PAA (available ions in the solution: - $-\mathrm{Zn}^{2+} ;-\boldsymbol{\Delta}-\mathrm{Cr}^{3+} ;-\mathbf{m -} \mathrm{Ni}^{2+} ;-\downarrow$ without heavy metal ions)

flocculant (9). The mixture stands for a complete separation of the precipitate. The waste after reagent cleaning (7) is separated from the precipitate by means of a vacuum filter (10) and sent to the reactor with a stirrer (2), simultaneously conducting a control measurement of the concentrations of contaminated water after precipitation. Bentonite was preloaded in a reactor with a stirrer (2) in amount of $5 \mathrm{~g} / \mathrm{dm}^{3}$ of water. The reactor (2) represents a cylindrical container, possibly with a removable lid, with a mixing device installed thereon. The of the mixer is driver with a vertical electric motor with a gear unit (3). The device is made of acid-resistant steel grades $08 \mathrm{X} 18 \mathrm{H} 10 \mathrm{~T}$, it has a enamel-proof coating. Upon completion of mixing, the PAA

Table 4. Results of calculations of fictitious rate of precipitation of sorbents in water

\begin{tabular}{|c|c|c|c|}
\hline Sorbent & $\mathrm{P}$ & Ua. $\mathrm{cm} / \mathrm{sec}$ & Uf. $\mathrm{cm} / \mathrm{sec}$ \\
\hline Bentonite & 0.52 & 0.0014 & 0.0027 \\
\hline $\begin{array}{c}\text { Bentonite }+ \\
\text { PAA }\end{array}$ & 0.81 & 0.0043 & 0.0053 \\
\hline
\end{tabular}




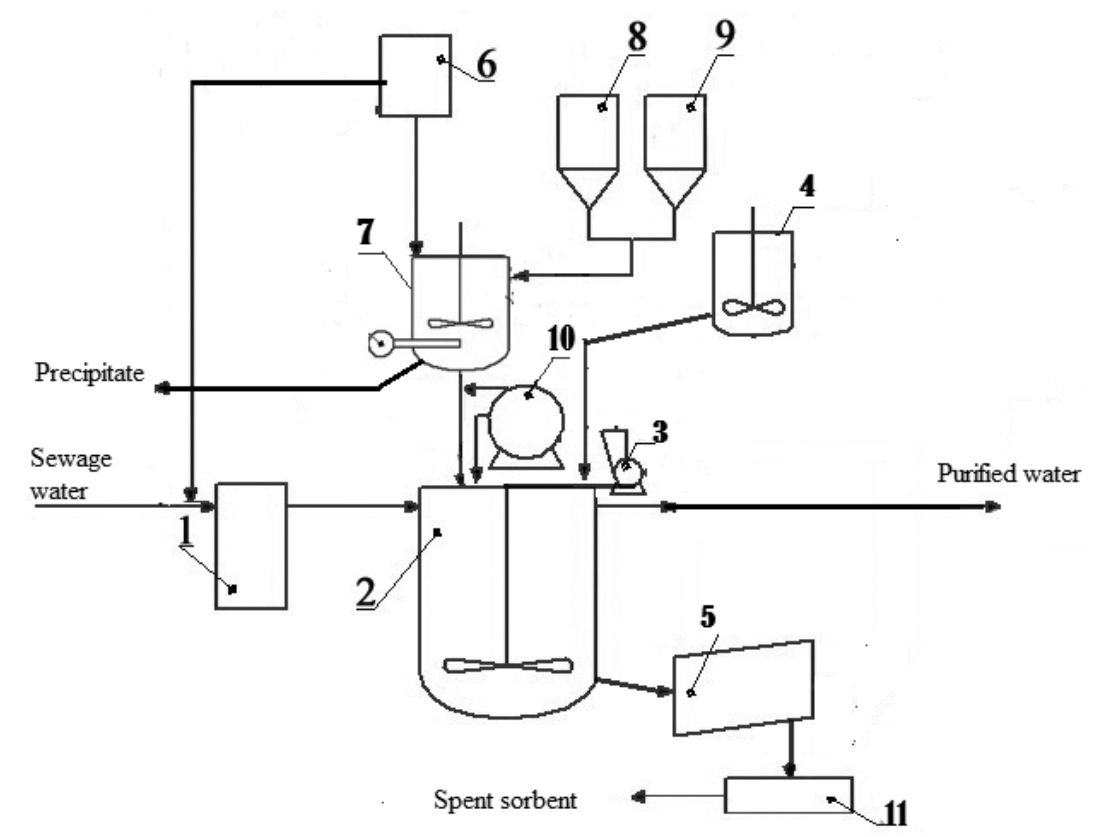

Figure 5. Principle technological scheme for purification of galvanic waste from heavy metal ions using natural disperse sorbents: 1 - collector, 2 - reactor for adsorption purification, 2 - sedimentation tank, 3 - engine for rotation of the mixer, 4 - container with a stirrer for preparation of a solution of PAA, 7 - reactor for chemical precipitation, 8,9 - capacities for storage of solutions of lime and flocculant, 5 - drum dryer, 10 - vacuum filter, 11 - bunker for spent bentonite

solution is dosed in the amount of $0.2 \%$ of the mass of bentonite to accelerate precipitation of pollutants (4). After complete precipitation (up to 1 hour) of the exchange products, the suspension is separated. The purified water can be reused in the production cycle.

The wet waste sorbent is fed to a drum type dryer (5), where it dehydrates and grinds into a fraction smaller than $0.5 \mathrm{~mm}$, and then goes to a storage vessel (11). The drying temperature can be taken as equal to $120^{\circ} \mathrm{C}$. Bentonite, saturated with cations of heavy metals can be used as a catalyst. Metal only is a good catalyst when it is in a fine dispersed state. A very high dispersion of the metal can be obtained by saturation of the inert carrier with the corresponding metal ions with the subsequent reduction of the metal.

While testing the proposed technology, the following benefits were identified:

- a valuable component - ions of heavy metals is removed from the industrial water;

- the possibility of using a cheap adsorbent natural bentonite with the further possible implementation in the national economy;

- implementation of the process of recycling water supply, which helps to save on enterprise resources and improve the environmental situation in the region.
The main technical and economic calculations indicate that the proposed technology has a satisfactory rate of profitability and will allow a modern entrepreneur to reimburse the investment for the introduction of new technology within a year and a half.

\section{CONCLUSIONS}

1. In the work, the feasibility of using modern bentonite clay as a natural sorbent capable of absorbing heavy metal ions with the aim of purifying sewage and improving its physicochemical and organoleptic parameters due to high adsorption, ion exchange and filtration properties was explored and scientifically substantiated. This approach will contribute to the inclusion of the environmental component in entrepreneurial activity no longer as an obstacle to development and inevitable costs, but as an area of additional opportunities, a new means of improving competitiveness through a relatively low cost.

2. It was experimentally proved that the maximum absorption of chromium, nickel and zinc ions occurs within 30 minutes, and practically complete - in $6-8$ hours. The level of sewage 
purification at various concentrations of pollutants and quantities of metered sorbent was determined. A rational dose is $5-8 \mathrm{~g}$ of bentonite per $1 \mathrm{dm}^{3}$ of contaminated water (provided that the initial concentration of the pollutant does not exceed $1000 \mathrm{mg} / \mathrm{dm}^{3}$ ).

3. In the form of isotherms and by means of statistical estimation, it was established that the experimental data are best described by the isomerism of the monomolecular adsorption of Langmuir; accordingly, the sorption of heavy metal ions occurs with the formation of molecular layers with the highest activity of the upper layer. The calculated constants from the Langmuir isotherm equation, as well as the sorption capacity of the studied bentonite clays in the range of investigated concentrations of heavy metal ions in solutions.

4. Addition of PAA solution at the end of the process can reduce the deposition time of the spent sorbent for 20 minutes and increase the degree of deposition by an average of $30 \%$. Within each graph there is a better precipitation of clay saturated with heavy metal ions compared to the clay-water system, which is most likely due to an increase in the size of saturated clay particles. However, the nature of the metal ion does not significantly affect the rate of deposition. The following parameters, such as average and fictitious velocities, as well as the relative amount of the resulting precipitate, were calculated to determine the precipitation rate of the sorbent particles.

5. The technology of wastewater treatment from heavy metal ions was developed, which involves the treatment of sewage with a concentration of heavy metals up to $0.5 \mathrm{~g} / 1$ by adsorption of natural disperse sorbents and subsequent deposition of the spent sorbent. It is recommended to use a spent dried sorbent as a catalyst.

\section{REFERENCES}

1. Adamenko Ya. S. et al. 2017. Territorial Normative of Quality of Hydroecosystems of Protected Territories. Hydrobiolog. J., 2(53), 50 - 58. doi:10.1615/ HydrobJ.v53.i2.50

2. Alfarra R. Sabreen et al. 2014. Removal of heavy metals by natural adsorbent: review. International Journal of Biosciences, 11, 130-139. doi: 10.12692/ijb/4.7.130-139.
3. Danchenko, Y. et al. 2017. Research into surface properties of disperse fillers based on plant raw materials. Eastern European Journal of Enterprise Technologies. 12(89), 20 -26. doi:10.15587/17294061.2017.111350.

4. Fiaizullina R.V. et al. 2017. The possibility of wastewater treatment of heavy metals by natural sorbent. 17th International Multidisciplinary Scientific Geo Conference SGEM 2017 Conference Proceedings, 29 June - 5 July, 2017, 17(52), 1027-1034. doi: 10.5593/sgem2017/52/s20.131.

5. Gomelya N. et al. 2018. Electroextraction of heavy metals from wastewater for the protection of natural water bodies from pollution. Eastern-European Journal of Enterprise Technologies. 10 (91), 55 61. doi:10.15587/1729-4061.2018.123929.

6. Goncharuk V.V. et al. 2009. Water treatment by baromembrane methods based on ceramic membranes. Journal of Water Chemistry and Technology. 31(6), 396-404. doi:10.3103/S1063455X09060083

7. Kołodyńska Dorota et al. 2017. Use of natural sorbents for removal of heavy metal ions. PRZEMYSŁ CHEMICZNY. 96, 1(5), 1139- 1145. doi: 10.15199/62.2017.5.33.

8. Malovanyy A. et al. 2013. Concentration of ammonium from municipal wastewater using ion exchange process. Desalination. 329, 93-102. doi:10.1016/j.desal.2013.09.009

9. Malovanyy A. et al. 2014. Combination of ion exchange and partial nitritation/Anammox process for ammonium removal from mainstream municipal wastewater. Water Science \& Technology. 70, 1, 144 - 151. doi: 10.2166/wst.2014.208.

10. Malyovanyy M. et al. 2013. Water sorption purification from ammonium pollution. Chemistry and chemical technology. 7(3), 355-358. doi:10.23939/ chcht07.03.355

11. Melnyk L. et al. 2015. Adsorption of Heavy Metals Ions from Liquid Media by Palygorskite. Chemistry \& Chemical Technology. 9(4). 467-470. doi: 10.23939/chcht09.04.467.

12. Petrus Roman et al. 2005. Heavy metal removal by clinoptilolite. An equilibrium study in multi-component systems. Water Research. 39 (5), 819-830. doi: 10.1016/j.watres.2004.12.003.

13. Petrushka I.M. et al. 2014. Cesium sorption intensification by complex natural sorbents from liquid radioactive media. Eastern-European Journal of Enterprise Technologies. V.5. 10(71), 47-50. doi: 10.15587/1729-4061.2014.28066/

14. Warchoł Jolanta, Petrus Roman. 2006. Modeling of heavy metal removal dynamics in clinoptilolite packed beds. Microporous and Mesoporous. 93(1-3), 29 - 39. doi: 10.1016/j.micromeso.2006.01.021. 
15. Seminska O.O. et al. 2016. Main regularities of reverse-osmotic water purification of phosphates. Water Chem. and Technology. 38(1), 39-44. doi:10.3103/S1063455X16010070.

16. Starchevskyy V. et al. 2017. The effectiveness of food industry wastewater treatment by means of different kinds of cavitation generators. Chemistry \& Chemical Technology. 11(3), 358-364. doi:10.23939/chcht11.03.358.

17. Starchevskyy V. et al. 2018. Determination of the cavitation influence on the destruction process of microorganism cells agglomerates. Chemistry \& Chemical Technology. 12(4), 462-465. doi: 10.23939/chcht12.04.462.

18. Vasylechko V.O. et al. 2003. Adsorption of cadmium on acid-modified Transcarpathian clinoptilolite. Microporous and Mesoporous Materials. 60(1-3), 183-196. doi: 10.1016/s1387-1811(03)00376-7.

19. Yadi M Gaouar et al. 2015. Adsorption of ammonia from wastewater using low-cost bentonite/chitosan beads. Desalination and Water Treatment. 57(45), 1-11, doi:10.1080/19443994.2015.1119747 